\title{
$|\||||||||||||||||||||$ 紹 |||||||||||||||||||| Fuzzy Systems in Romania in the context of Balkans and of Europe
}

\author{
H.N. Teodorescu*
}

\section{Background}

Romania is known as one of the countries where fuzzy systems were first developed.

In Romania worked the great scientist Grigore Moisil, one of the forerunners of fuzzy systems, and one of the few scientists in the world to do and encourage fuzzy systems research in the first five years after Professor Lotfi Zadeh has introduced his seminal concepts. As early as 1938, Grigore Moisil has developed the theory of reasoning under multiple and infinite-valued logics, and he was the first to write a book on fuzzy systems (a textbook for his course in 1971, in Italy). Unfortunately, his sudden death (in 1972, in Canada) left this book un-published until 1976 .

Also from Romania came two reputed fuzzy systems scientists, Constantin V. Negoita and Dan Ralescu. Their contributions are well known. Incidently, the second book on fuzzy systems in the world was published in Romania (in Romanian language), by C.V. Negoita and D. Ralescu, in 1975. Other reputed scientists from Romania are D. Butnariu (who introduced the theory of fuzzy games), and Vincentiu Dumitru (researches in fuzzy linear programming and optimization).

Romanian school in fuzzy systems decayed after the death of Prof. Moisil and the leaving of Romania by three of the above mentioned scientists. In the early ' $80 \mathrm{~s}$ a few research was performed in fuzzy systems in Romania.

However, the field was revigourated and re-established as a major field of research by

* Visiting Professor at FLSI and Kyusyu Institute of Technology the creation of the present fuzzy systems engineering Iasi school after 1985. In 1988, the Grigore Moisil Seminar was established, and after 1990, new organizations emerged, all having as starting point this Seminar.

\section{Scientific Organizations}

\subsection{The Romanian Society for Fuzzy Systems (RSFS)}

In Romania, the main organization in the field is the Romanian Society for Fuzzy Systems (RSFS) - a non-governmental, non-forprofit, educational and scientific organization.

RSFS was founded in January 1990, as a result of the mature activity existing in the framework of Grigore Moisil Workshop on Fuzzy Systems, Iasi. During thd last years, as a recognition of its worth, this Society got the support of the Romanian Academy-Iasi Branch, from the Ministry of Education and Science, Romania, and also from UNESCO-CEPES (Centre Europeen pour l'Enseignement Superieur).

Now, in Romania there are a great number of fuzzy systems researchers (about 200), and also an important number of mature researchers, including: Ioan Tofan, Ion Bogdan, Dan Galea, Vitalie Belous, Alexandru-Puiu Tacu, Gheorghe Radu, Mirela Stefanescu, Dan Cristea, Mircea Chelaru, Nicu Curteanu, Victor Grigoras, Adrian Stoica, Claudiu Dumitrascu, Lacramioara Pavel, Florin Grigoras etc. (in Iasi city) ; Vincentiu Dumitru, Edmond Nicolau, Florica Luban, Mihai-Dragos Stoica, Afrodita Iorgulescu, Emil Sofron etc. (in Bucharest city) ; Traian Buhaescu (Galati city) ; Dan Dumitrescu, Pop Ioan etc. (Cluj city) etc.

In Iasi city there are more than 50 people 
performing research in fuzzy systems, and five professors (Dan Galea, Calin Ignat, Mihai Lucanu, V. Munteanu, and H.N. Teodorescu) having doctoral students in fuzzy systems.

The main organizations in Iasi city, performing fuzzy research, are: CERFS (see below), ITI (see below), the University of Iasi (with a strong group in fuzzy sets algebra), Polytechnic Institute of Iasi (fuzzy engineering), Center for Inventics, and Center for Research in Economics.

RSFS Headquarters address is :

RSFS, Academy Building, Copou 8, Iasi 6600, Romania.

\subsection{The Balkanic Union for Fuzzy Systems \&} A.I.

The Romanian Society for Fuzzy Systems gave rise to an international regional organism, The Balkanic Union for Fuzzy Systems \& A.I. (BUFSA). This Union was established in October 1990, during the Second (International) Symposium on Fuzzy Systems, held in Iasi, under the organization of RSFS, and of Grigore Moisil Workshop.

The Balkanic Union includes scientists and researchers from all Balkanic area (including Republic of Moldova), on an individual basis. BUFSA is also organizing regional (national) chapters, preferably as national societies, but membership to such a society is not requested for BUFSA membership.

BUFSA is organizing in 1992 its second international conference, in Trabzon, Turkey.

BUFSA Headquarters address is : BUFSA, Academy Building, Copou 8, Iasi 6600 , Romania.

\subsection{Grigore and George Moisil Foundation}

This foundation was established in January 1992, by Horia-Nicolai Teodorescu and a few members of the Romanian Society for Fuzzy Systems, and of the Balkanic Union for Fuzzy Systems \& A.I.
The foundation is aimed to encourage the research in fuzzy systems and A.I. in Romania, as well as in the Balkanic area, and to give recognition to outstanding scientists from all over the world. Real-life applications and technology transfer from Romania abroad, and from abroad in Romania are also envisaged.

The Foundation has established national prizes, to encourage young researchers.

The Awarding Board of Grigore and George Moisil Foundation includes : Prof. Viorica Moisil (the wife of late Professor Grigore Moisil), Prof. Diana Moisil (the sisterin-law of late Professor Grigore Moisil), Prof. Dr.dr.h.c. Hans-Jurgen Zimmermann, Prof. Takeshi Yamakawa, Prof. Erich Peter Klement, Prof. D.Ralescu, Prof. A. Kaufmann, Prof. D. Dubois, Prof. H. Prade, Prof. Dan Butnariu, Prof. Jaime Gil Aluja, Prof. M. Delgado, Prof. J. L. Verdegay, Prof. H.N. Teodorescu.

The Foundation is establishing an international-level prize aimed to give recognition to outstanding researchers in fuzzy systems and related fields. This prize is to be considered a prestige, not an encouragement award, i.e. a recognition of the highest level scientific and organizational contributions already achieved in fuzzy systems and in related fields. No issue will be took into account when nominating the awardees, but the level of the contribution to the field. No restrictions related to country of origin, nationality, citizenship, race, sex, religion, or age can be accepted.

Any other scientific, academic, or professional bodies in the field are invited to join the board of this Foundation.

Grigore and George Moisil Foundation address is :

C.P. 1322 , Of 6 , Iasi 6600 , Romania.

\section{The main research organizations}
3.1 Center for Education and Research in Fuzzy Systems \& A.l. (C.E.R.F.S.) lasi


The Center for Education and Research in Fuzzy Systems and A.I. was established in 1990 , by the Senate of the Polytechnic Institute of Iasi, and six month later it was established as a national-level center by the Romanian Ministry of Educatiion and Science.

CERFS is a non-for-profit, academic organization, aimed to play a major part to the development of education and research in fuzzy systems and A.I. in Romania. Its activities are, for the most part, supported by the Romanian Ministry of Education and Science. CERFS is directly connected to the Polytechnic Institute of Iasi, being an autonomous department of it.

In the frame of the Center, a researchgrade weekly seminar on fuzzy systems and A. I. is held, in cooperation with the Institute for Theoretical Informatics, Iasi. Students are preparing here their Master thesis, and starting 1991, a Ph.D. level teaching was established (four Ph.D. students now in CERFS).

The Center is employing 12 peoples, including two research engineers and a librariandocumentarist. The basis of the activity relies on the teachers from the Institute, and also from the University of Iasi.

CERFS is contributing to the publication of the international journal 'Magazine for Fuzzy Systems \& A.I.' - the official publication of the Balkanic Union for Fuzzy Systems \& A. I.CERFS is also publishing a series of Research Reports (which can be got by asking for to the Center).

CERFS is an institutional member of IACEE-International Association for Continuing Engineering Education. Moreover, CERFS is actively participating in the activities of IEEE Romanian Branch, of the Balkanic Union for Fuzzy Systems \& A.I., of the A.M.S.E. International Association (based in France), and in some of the activities of CEPES (Centre Europeene pour l'Enseignement Superieur).

CERFS wished to contribute to the increasing standing of education and research in Romania, East Europe, and all over the world. Following, CERFS has signed cooperation agreements with FLSI (Iizuka, Japan), AMSE (France), ELITE (Aachen, Germany), Academy of Science, Chisinau, R.Moldova, FLLL (Linz, Austria), a.s.o.

CERFS is opened to the participation in any international level activities within its scope, and to the establishment of cooperation agreements with similar bodies around the world.

CERFS address is :

CERFS, Polytechnic Institute of Iasi, Copou 19, Iasi 6600, Romania.

\subsection{The Institute for Theoretical Informatics (ITI), lasi \\ This Institute is supervised and supported} by the Romanian Academy, and represents one of the most powerful and modern advanced research institutes in Romania. The Institute is organized on three Laboratories:

1. Laboratory for Signal Processing, Fuzzy Systems and Neural Networks;

2. The Laboratory for Image Processing ;

3. The Laboratory for Artificial Intelligence.

The Institute develops both theoretical and applied research and products designed here are already commercially available.

The Institute much supports by its researchers in the Romanian Society for Fuzzy Systems, and has a major contribution to the organization of international symposia and conferences organized by RSFS.

Many young researchers from the Institute are doctoral students in fuzzy systems and neural networks.

\section{Symposia and conferences}

Every year, the Romanian Society for Fuzzy Systems (RSFS), the Center for Fuzzy Systems and A.I., and the Institute for Theoretical Informatics, Iasi, are organizing an interna- 
tional Symposium on Fuzzy Systems and A.I. (IFSAI). In 1992, this Symposium is at its fifth edition.

Also, RSFS is participating to the organization of an international symposia with AMSE, France. These AMSE symposia are held annually, each year the place where the symposium is held being changed inside Europe. Up to now, the AMSE Symposia on Fuzzy Systems and Signals where held in Turkey (1988), England (1989), Yugoslavia (1990), Poland (1991), and Switzerland (1992).

\section{Publications}

\subsection{Periodical Publications}

The fuzzy systems international and national editorial activity of RSFS has leaded to the publication of new journals and of a great number of books.

The first Romanian journal in fuzzy systems was Magazine of the Romanian Society for Fuzzy Systems (RSFS Magazine), first issued in March 1990). After the establishment of the Balkanic Union for Fuzzy Systems, RSFS Magazine gave rise to the international journal Magazine for Fuzzy Systems \& A.I. (in English), aimed to be a general magazine for fuzzy systems and related topics.

Starting 1991, a new international scientific journal was established with the support of the Romanian Academy, and by international cooperation : Fuzzy Systems and A.I. Reports

\section{\& Letters}

The Editors of this journal are:H.N. Teodorescu, T. Yamakawa, H.J. Zimmermann. The Honorary Editor is Prof. L.A. Zadeh. The Chairman of the Editorial Board is Prof. M. Draganescu. The Editorial Board includes some of the most reputed scientists in the field.

This new journal is aimed to offer a fast communication medium for short papers ('letters', up to four printed pages), and also for survey papers. The Journal complements the existing other journals in the field.

\subsection{Other publications}

RSFS, CERFS and BUFSA, in cooperation with AMSE-France, and with Polytechnic Institute of Iasi, and Iasi University, are publishing two series of volumes:AMSE Series in Fuzzy Systems and Signals (published in France), and Fuzzy Systems and A.I. Series,

published in Romania (but in English language).

Up to now, more than ten volumes were issued in these series.

\section{International cooperation projects}

\subsection{Cooperation between Central and East \\ European Countries in Education and Research in Fuzzy Systems}

There is an old tradition of economic and cultural cooperation between countries from the Central and the East European areas. They are sharing a common, most interrelated historical development, and medieval scholastics are known to move from one center of this part of Europe, to another, in a natural way. Thus, there is no surprise that these two regions share common interests and also similar points of views in many cultural issues.

The foundation in 1992 of the Fuzzy Logic Linz Laboratorium (FLLL) is expected to further strengthen the cooperative potential of Austria.

In Czecho-Slovakia there is a research groups in the Academy of Science, working mainly on the logic foundations, and also on applications in physics.

These bodies already established and partly realized common researches, common organization of symposia etc.

The first major cooperation project is related to the cooperation between Austria, Czecho-Slovakia, and Germany with countries from the Balkans, as represented in BUFSA. Apart the common organization of interna- 
tional symposia and conferences, an International Summer School, scheduled for 1993, is envisaged. In this summer school, devoted to Fuzzy Systems and Intelligent Techniques, students and teachers from about 10 European countries are expected to participate.

The second major cooperation project is relatied to ELITE Foundation (Aachen, Germany). The project is expected to be established end of 1992.

\subsection{The EEEA Project : Nurture the Spirit of Co-operation in Education and Research}

The EEEA Project represents a pilot project for East Europe \& East Asia Cooperation in Education and Research in Fuzzy Systems \& A.I., and is aimed to be a general framework, and an example for similar projects in the future.

The EEEA project was tentatively established in 1992, and probably represents the most ambitious cooperation plan in education and research ever established between Japan, and Southeastern European countries.

Following a two-years most successful cooperation between Fuzzy Logic Systems Institute, and Kyusyu Institute of Technology, from one side, and the Balkanic Union for Fuzzy Systems, the Romanian Society for Fuzzy Systems, and the Center for Fuzzy Systems \& A.I., Polytechnic Institute of Iasi, on the other side, these organizations consider that time is for a mature cooperation envisaging a broader development of common fruitful activities, including both educational activities and common research (joint publication of papers, joint application for patents etc.).

Following, these organization have established the EEEA Project, aimed to contribute to the general development of cooperaion between researchers from East Asia (now : from Japan), and East Europe, as well as to a better mutual understanding between the peoples of their countries. The organizers of this project will be glad to have any advice and opinion on the Project, from all over the world.

\section{Conclusions}

To conclude, the Romanian school in fuzzy systems and A.I. is prepared to bring its contribution to the development of these fields at an international scale, and is confident in the part it can plan in the future.

Romania has now a very large group of both mature and young researchers able to accomplish the task of developing advanced, sound theoretical and technological developments in fuzzy systems, neural networks and related fields.

$<$ Contact Address $>$

H.N. Teodorescu

Center for Fuzzy Systems \& A.I.

Copou Bivd. nr. 19

Iasi 6600

Romania

Phone: + 40-98-142283

Fax : + 40-98-147923

" : + 40-81-47923

\section{$<$ Biographical Note $>$}

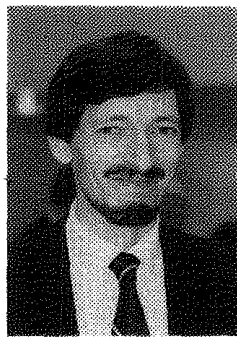

H.N. Teodorescu

Director of Center for Fuzzy Systems \& A.I. (CERFS)

General Secretary of the Balkanic Union for Fuzzy Systems and Applications (BUFSA)

Vice President of Romanian Society for Fuzzy Systems (RSFS)

Visiting Professor \& International Scientific Committee Member of FLSI

Graduated the Faculty of Electronics, Technical University of Bucharest, Romania, 1975.

Doctor in Technical Physics, Polytechnic Institute of Iasi, Romnania, 1981. 